3. Гудков, Д.Б. Теория и практика межкультурной коммуникации/ Д.Б.Гудков. М.: Гнозис, 2003. 288

4. Назарова Р. 3., Золотарев М.В. Прецедентные феномены: проблемы дифиниции и классификации прецедентных феноменов / / Известия Саратов-ского университета. Новая серия. Серия Филология. Журналистика. Российская и зарубежная филология. 2015. №2. Саратов: Известия Саратовского университета. Новая серия. Серия Филология. Журналистика. Российская и зарубежная филология. Российская и зарубежная филология, 2015. [Электронный ресурc] URL: https://cyberleninka.ru/article/n/pretsendentnye-fenomeny-problemy-definitsii-i-klassifikatsiipretsedentnyh-fenomenov

5. ИноПресса.ру [Электронный ресурс] URL: https://www.inopressa.ru

6. ИноСМИ.ру [Электронный ресурс] URL: https://inosmi.ru

7. Deutsche Welle [Электронный pecypc] URL: http://www.dw.com/ru/темы-дня/s-9119

\title{
Прокопьева Н.Н. \\ Функционально-прагматический потенциал категории количества в немецкоязычных медиатекстах (на материале интервью)
}

Нижегородский государственный лингвистический университет им. Н.А. Добролюбова

(Россия, Нижний Новгород)

doi: $10.18411 / l j-02-2021-261$

idsp: ljournal-02-2021-261

\section{Аннотация}

В статье рассматриваются языковые средства разных уровней, передающие значение количества, и их функции в текстах интервью. Установлена полифункциональность языковых единиц, называющих количество. Самостоятельно или в комбинации с другими средствами они служат для реализации основных функций СМИ - функции информирования и функции воздействия на аудиторию.

Ключевые слова: категория количества, функции СМИ, интервью, прагматический потенциал, речевое воздействие

\section{Abstract}

The article discusses language means of different levels that convey the meaning of quantity, and their functions in interview texts. The polyfunctionality of linguistic units, naming the quantity, has been established. Alone or in combination with other means, they serve to implement the main functions of the media - the function of informing and the function of influencing the audience.

Keywords: the category of quantity, functions of the media, interview, pragmatic potential, speech effects

Язык средств массовой информации издавна привлекает внимание исследователей, представляющих самые разные научные отрасли, так или иначе ориентированные на изучение человека и/или социума. Это неудивительно, учитывая, какую роль массмедиа играют в жизни современного общества. К базовым функциям СМИ относят прежде всего функции информирования и воздействия, причем, по мнению некоторых ученых, «особенностью языка современных СМИ является возрастание значимости воздействующей функции» [3, с. 28]. С.Ю. Лисова, исследуя политические функции СМИ, отмечает, что «социально значимые функции воздействия и взаимодействия представляют особый интерес в прагматическом смысле, поскольку предусматривают передачу установок, предписывающих определенное влияние на коммуниканта и его адекватную реакцию в соответствии с нормой поведения» [4, с. 3]. Языковые средства, используемые журналистами для реализации данной функции, постоянно находятся в центре внимания лингвистов. Целью нашего 
исследования является анализ используемых в материалах немецкой прессы языковых средств, так или иначе связанных с понятием количества. Материалом для исследования послужила серия интервью с доктором Джиханом Челиком, который работает в клинике города Дармштад (ФРГ). Данные интервью, опубликованные в период с мая 2020 года по настоящее время одной из ведущих газет Германии „Frankfurter Allgemeine Zeitung“, посвящены самой актуальной в данный момент проблеме - пандемии коронавирусной инфекции, охватившей весь мир. Очевидно, что это серьезное заболевание, кардинально изменившее жизнь не только отдельных людей, но и целых стран, стало темой номер один для мировых СМИ. При этом авторы многочисленных публикаций, освещающие в своих материалах данную проблему, ставят своей целью не только информирование общественности о положении дел, но и формирование в обществе определенного отношения к существующим угрозам, связанным с коронавирусом, и трансляцию определенных поведенческих установок.

Как уже отмечалось, арсенал языковых средств, используемых для реализации данной цели, весьма широк и неоднократно описан в лингвистической научной литературе. Наше внимание привлекли используемые в текстах интервью языковые единицы, выражающие количественные значения, интерес к которым обусловлен, среди прочего, безусловной значимостью самой категории количества, которая не только фигурирует во множестве наук, но и «является естественной и неотъемлемой частью и обыденного мировосприятия, сопровождающего повседневную жизнь человека, о чем свидетельствует наличие в лексиконе любого языка значительного числа языковых единиц, ... так или иначе вербализующих данную мыслительную категорию» [5, с. 168]. В своем исследовании мы исходим из предположения, что использование в медиатекстах, и в частности, в анализируемых интервью языковых единиц, выражающих понятие количества, обусловлено не просто желанием журналистов сообщить читателям некоторые объективные данные, связанные с распространением коронавирусной инфекции, с протеканием болезни и т.П., но и другой прагматической интенцией - оказать влияние на аудиторию, выработать определенное отношение к описываемой проблеме и побудить читателей к рекомендуемым врачами и властями действиям (например, к соблюдению социальной дистанции, ношению маски) либо, наоборот, удержать их от нежелательных действий (посещения общественных мест, участия в массовых мероприятиях). Как подчеркивает Г.Н. Третьякова, «ментальная схема «количество»...может эффективно использоваться для создания высокого потенциала воздействия текста» [6, с. 32].

И.В. Беляева, исследовавшая прагматическое содержание количественной оценки, отмечает, что «экспонентами количественных значений являются объединения разноуровневых средств, в ряду которых регулярны имена числительные, количественные прономинативы, квантитативные существительные, глаголы некоторых способов глагольного действия, числовые формы всех частей речи и прежде всего - имени, а также типизированные синтаксические структуры» [2, с. 5]. Логично, что имя числительное называется первым в этом ряду, поскольку категориальное значение данной части речи заключается именно в назывании числа, количества предметов. Значимость количественных данных для исследуемого материала подтверждается и тем фактом, что все 7 проанализированных интервью начинаются с одного и того же вопроса: «Wie ist aktuell die Lage?“ [7; 8; 9; 10; 11; 12; 13] - «Каково положение дел на данный момент?». Очевидно, что интервьюера интересует прежде всего количество ковид-инфицированных, находящихся на лечении в клинике, в которой работает доктор Челик. Характерно, что числа в ответе на этот вопрос варьируются от двузначных до ноля - в зависимости от месяца, в котором было взято интервью. Так, в период первой волны пандемии, в мае 2020 года, доктор называет большее число больных, чем летом, по ее окончании, и в конце сентября, до начала новой волны, ср.: май: «Die Anzahl der Verdachtsfälle ist an manchen Tagen hoch, dann 
bekommen wir 16 bis 20 Patienten für unsere Isolierstation“" [7] - «Количество подозрений на ковид в некоторые дни велико, тогда в нашем инфекционном отделении от 16 до 20 пациентов»; июнь: «Wir haben seit circa zwei Wochen keinen neuen positiven Fall mehr gehabt» [10] - «Примерно две недели у нас не было ни одного нового подтвержденного случая»; сентябрь: «Aktuell haben wir zwei Covid-19-Patienten, ein Patient wird auf der Intensivstation behandelt, eine Patientin auf der Isolierstation» [12] - «В настоящее время у нас два больных Covid-19, один пациент проходит лечение в отделении интенсивной терапии, одна пациентка - в инфекционном отделении». При этом обращает на себя внимание тот факт, что, называя конкретные цифры, доктор Челик зачастую сопровождает их комментарием, в котором использует и другие лексические единицы, связанные с понятием количества. Как правило, это глаголы или производные от них имена существительные, которые указывают на изменение количества: sinken (снижаться), abnehmen (уменьшаться), steigen (расти, увеличиваться) и др., ср.: «In den vergangenen drei Wochen ist es zu einem Anstieg der Zahl der positiv getesteten Patienten gekommen... Bei dieser Zahl müssen wir langsam ans Expandieren denken» [11] - «3a прошедшие три недели произошло увеличение количества положительных тестов на ковид... При таких цифрах мы должны думать о расширении». Как и сами имена числительные, такие лексемы могут выполнять двоякую функцию: объективного информирования читателей о положении дел и одновременно оказания определенного воздействия - предупреждение о росте числа заболевших имплицирует призыв соблюдать осторожность, не расслабляться.

Кроме того, имена числительные используются в исследуемых интервью еще в одном типичном случае - при назывании возраста пациентов: «Wir haben immer auch jemanden auf der Station, der 20 oder 30 Jahre alt ist» [7] - «У нас в отделении есть пациенты, которым и 20, и 30 лет»; «Unsere Patienten sind zwischen 40 und 85 Jahre alt» [13] - «Нашим пациентам от 40 до 85 лет». Эти объективные данные направлены на достижение конкретного прагматического эффекта: их следует рассматривать как предостережение молодым людям, зачастую проявляющим беспечность. Известно, что в самом начале пандемии было распространено мнение, что ковид опасен прежде всего для людей старшего возраста и что молодые люди реже болеют и легче переносят это заболевание. Доктор Челик не опровергает это мнение, но подчеркивает, что ковид может представлять опасность для людей любого возраста.

Еще одним языковым средством, реализующим категорию количества, является имя прилагательное, которое, как правило, соотносится не с числом, но с величиной определенного объекта, что также является одним из аспектов количества. Об этом говорил еще Аристотель: «Ведь количество есть множество, если оно счислимо, и величина - если измеримо» [1, с. 164]. Анализ текстов интервью показал, что с помощью имен прилагательных также может быть достигнут определенный перлокутивный эффект, причем характерно, что доктор Челик говорит преимущественно о вещах, которые должны успокоить аудиторию или, по крайней мере, не нагнетать обстановку и не провоцировать панику. Так, он постоянно подчеркивает, как быстро врачебное сообщество учится, получает новые данные, оказывает помощь пациентам: «Das alles müssen wir sehr schnell machen» [7] - «Bce это мы должны делать очень быстро»; «...sorgen wir deswegen dafür, dass sie so schnell wie möglich in ein peripheres Haus verlegt werden» [7] - «...поэтому мы стараемся как можно скорее перевести их в отдельный корпус». Такое воздействие Г.Н. Третьякова называет «терапевтическим», позволяющим «достаточно быстро восстановить душевное равновесие, предотвратить развитие эмоционально-психологического кризиса» $[6$, с. 25].

Говоря об именах прилагательных, необходимо упомянуть грамматическую категорию, также являющуюся языковым средством выражения количественных 
отношений. Это категория степеней сравнения имен прилагательных и наречий, которая указывает на степень качества, признака предмета, явления или действия - то есть на то, что определенный признак проявляется в большей или меньшей мере. Так как за прошедшее с начала пандемии время ситуация в мире, в том числе и в Германии, сильно изменилась, доктор Челик постоянно указывает на произошедшие изменения как положительного, так и отрицательного характера. Так, в одном из интервью он выражает свою обеспокоенность тем фактом, что социально незащищенные (а проще говоря, бедные) слои населения больше страдают от пандемии: «Ärmere Menschen sind weniger gut an Ärzte angebunden ... Die Menschen leben auf engerem Raum und arbeiten in Berufen, in denen sie vielen Kontakten ausgesetzt sind» [8] - «Более бедным людям менее доступна врачебная помощь... Они живут в более стесненных условиях и занимаются работой, при которой они вынуждены контактировать со многими людьми». С другой стороны, доктор подчеркивает, что за прошедшее время врачи многому научились, и это увеличивает шансы больных на успешное лечение и быстрое выздоровление: «Wir sind selbstsicherer im Umgang mit der Erkrankung.... Zweitens können wir die Patienten besser behandeln und besser abschätzen, wie die Krankheit wahrscheinlich verlaufen wird» [11] - «Мы более уверенно подходим к лечению этой болезни... Во-вторых, мы можем лучше лечить пациентов и лучше оценить вероятное течение болезни». Данные утверждения также должны немного успокоить перегруженных негативной информацией читателей.

Другим грамматическим средством, имеющим непосредственное отношение к категории количества, является категория числа: по мнению Г.Н. Третьяковой, она хоть и не обладает сама по себе достаточно заметным потенциалом речевого воздействия, но «в совокупности с другими средствами, порождаемыми в речи за счет активизированной ментальной схемы Количество, ее потенциал значительно возрастает и становится доступным для лингвистического анализа» [6, с. 25]. В исследуемых текстах нами были зафиксированы интересные случаи противопоставления существительных в единственном числе существительным во множественном числе, что создавало грамматическую антитезу, которая, как известно, является эффективным стилистическим приемом для создания контраста, акцентирования различий: «Es wird viel getestet, um diesen einen Patienten nicht zu verpassen, der viele andere Menschen anstecken kann» [10] - «Проводится много тестов, чтобы не пропустить этого одного пациента, который может заразить многих других». Однако более распространенным является другой вид антитезы, образованный с помощью антонимов: «Die wenigsten sind Reiserückkehrer, die meisten haben sich angesteckt, weil sie in prekären Verhältnissen arbeiten oder wohnen» [11] - «Вернувшихся из путешествий меньшинство, большинство заразились, потому что они работают или живут в опасных условиях». Прагматический потенциал антитезы в приведенном высказывании усиливается благодаря употреблению данных местоименных прилагательных в превосходной степени. Еще одним интересным примером антитезы, основанной на лексических значениях прилагательных, содержащих сему количества, является следующее высказывание доктора Челика о лекарстве, которое должно доказать свою эффективность, с одной стороны, и безопасность, с другой: «Еs muss durch Studien erst noch belegt werden, dass es wirkungsvoll ist und risikoarm gegeben werden kann» [13] - «Сначала исследованиями должно быть подтверждено, что оно эффективно и безопасно». Количественное значение выражается в данном случае с помощью полусуффиксов имен прилагательных -voll (букв. «богатый, полный чеголибо») и -arm («бедный»).

Таким образом, проведенный анализ текстов интервью показал, что категория числа, находящая свое отражение на разных уровнях языка, обладает 
полифункциональностью, то есть способна служить реализации как функции информирования, так и функции воздействия на широкую аудиторию.

$$
* * *
$$

1. Аристотель. Сочинения: в 4 т. М.: Мысль, 1976 - 1984.

2. Беляева И.В. Прагматическое содержание количественной оценки: автореф. дисс. ... к. филол. н. Краснодар, 2005. $26 \mathrm{c.}$

3. Ларина Т.В., Озюменко В.И., Пономаренко Е.Б. Языковые механизмы манипулирования общественным мнением в английских и русских информационных текстах // Вестник Российского университета дружбы народов. Серия Лингвистика. 2011. № 2. С. 28-37.

4. Лисова С.Ю. Политические функции СМИ // Вестник ИГЭУ, 2011. Выпуск 2 [Электронный pecypc]. URL: https://cyberleninka.ru/article/n/ politicheskie-funktsii-smi/viewer (дата обращения: 03.02.2021).

5. Прокопьева Н.Н. Концепт «количество» во фразеологической подсистеме немецкого языка // Лингвистика XXI века: традиции и новации: сборник трудов по материалам международной научной конференции памяти профессора В.В. Лазарева. Пятигорск: ПГЛУ, 2016. С.167-174.

6. Третьякова Г.Н. Число - текст - речевое воздействие // Вестник Минского государственного лингвистического университета. Серия 1. Филология. № 3. Минск: МГЛУ, 1998. С. 20-32.

7. https://www.faz.net/aktuell/gesellschaft/gesundheit/coronavirus/arzt-interviews/covid-19-arzt-iminterview-in-den-naechsten-wochen-muessen-wir-wohl-wieder-mehr-arbeiten-16749033.html ～(дата обращения: 03.02.2021).

8. https://www.faz.net/aktuell/gesellschaft/gesundheit/coronavirus/arzt-interviews/corona-arzt-ueberobdachlose-patienten-und-lungenschaeden-16771004.html (дата обращения: 03.02.2021).

9. https://www.faz.net/aktuell/gesellschaft/gesundheit/coronavirus/arzt-interviews/arzt-im-interview-jedercovid-19-patient-ist-ein-risikopatient-16788721.html (дата обращения: 03.02.2021).

10. https://www.faz.net/aktuell/gesellschaft/gesundheit/coronavirus/arzt-interviews/corona-arzt-uebersuperspreader-und-lockerungsmassnahmen-16813335.html (дата обращения: 03.02.2021).

11. https://www.faz.net/aktuell/gesellschaft/gesundheit/coronavirus/arzt-interviews/arzt-ueber-isolierstationfuer-corona-kranke-im-klinikum-darmstadt-16926382.html (дата обращения: 03.02.2021).

12. https://www.faz.net/aktuell/gesellschaft/gesundheit/coronavirus/arzt-interviews/corona-arzt-im-interviewremdesivir-kann-sehr-hilfreich-sein-16970818.html (дата обращения: 03.02.2021).

13. https://www.faz.net/aktuell/gesellschaft/gesundheit/coronavirus/arzt-interviews/covid-19-arzt-iminterview-mehr-als-die-haelfte-der-patienten-waren-zu-spaet-dran-16994112.html (дата обращения: 03.02.2021).

\section{Садуов Р.T. \\ Отношение к визуальным элементам культурно-языкового ландшафта города} ФГБОУ ВО «Башкирский государственный университет» (Россия, Уфа)

doi: $10.18411 / l j-02-2021-262$

idsp: ljournal-02-2021-262

\section{Аннотация}

Настоящая статья посвящена анализу результатов социологического исследования по поводу отношения жителей города Уфа к элементам культурноязыкового ландшафта. Выяснилось, что респонденты, в целом, довольны визуальным оформлением города. Они в высокой степени заинтересованы в сохранении дореволюционного и советского наследия, и при этом положительно относятся к современной архитектуре города.

$$
\text { Ключевые слова: языковой ландшафт, социологический опрос, }
$$
социолингвистика, культурный ландшафт, архитектура

\section{Abstract}

This article analyzes the results of a sociological study on the attitude of the residents of the city of Ufa to the elements of cultural and linguistic landscape. It turned out that the respondents, in general, are satisfied with the visual design of the city. They are highly 